OPEN ACCESS

Edited by:

Tzi Bun Ng,

The Chinese University of Hong Kong,

Hong Kong

Reviewed by:

Osmar Nascimento Silva,

Universidade Católica Dom Bosco,

Brazil

Zhi Ruan,

Zhejiang University, China Pedro Ismael Da Silva Jr.,

Instituto Butantan, Brazil

${ }^{*}$ Correspondence:

Sun C. Kang

sckang@daegu.ac.kr

Pradeep Kumar

pkbiotech@gmail.com

Vivek K. Bajpai

vbajpai04@yahoo.com

Specialty section: This article was submitted to Antimicrobials, Resistance and Chemotherapy,

a section of the journal

Frontiers in Microbiology

Received: 23 May 2017 Accepted: 22 November 2017 Published: 06 December 2017

Citation:

Khan I, Bahuguna A, Kumar P.

Bajpai VK and Kang SC (2017) Antimicrobial Potential of Carvacrol against Uropathogenic Escherichia

coli via Membrane Disruption, Depolarization, and Reactive Oxygen

Species Generation.

Front. Microbiol. 8:2421.

doi: 10.3389/fmicb.2017.02421

\section{Antimicrobial Potential of Carvacrol against Uropathogenic Escherichia coli via Membrane Disruption, Depolarization, and Reactive Oxygen Species Generation}

\author{
Imran Khan ${ }^{1}$, Ashutosh Bahuguna ${ }^{1}$, Pradeep Kumar ${ }^{*}$, Vivek K. Bajpai ${ }^{3 *}$ and \\ Sun C. Kang ${ }^{1 *}$
}

${ }^{1}$ Department of Biotechnology, Daegu University, Gyeongsan, South Korea, ${ }^{2}$ Department of Forestry, North Eastern Regional Institute of Science and Technology, Nirjuli, India, ${ }^{3}$ Department of Applied Microbiology and Biotechnology, Yeungnam University, Gyeongsan, South Korea

Bacterial resistance to antibiotics poses a serious threat to cure diseases associated with microbial infection. Among the resistant bacteria, extended-spectrum $\beta$-lactamase (ESBL)-producing bacteria are the most concerned one as they encode the enzyme $\beta$-lactamase that confers resistance to most $\beta$-lactam antibiotics. The present study was carried out to determine the antimicrobial potential and the principle mechanism of action of carvacrol against ESBL Escherichia coli isolated from ascitic fluid of a patient having a urinary tract infection. Carvacrol exhibited a minimum inhibitory concentration (MIC) of $450 \mu \mathrm{g} / \mathrm{ml}$ at which it reduced $E$. coli cell counts significantly in a timedependent manner. Carvacrol completely diminished the growth of $E$. coli after $2 \mathrm{~h}$ of incubation at its MIC. Fluorescent imaging displayed the elevated reactive oxygen species level and bacterial membrane depolarization leading to E. coli cell death in presence of carvacrol at its MIC. Furthermore, carvacrol displayed a severe detrimental effect on bacterial membrane disruption and cellular material release. In addition, a significant effect of carvacrol at sub-inhibitory concentration was observed on motility of E. coli cells and invasion of human colon HCT-116 cells in an ex vivo model. Based on the results, we conclude a potential antimicrobial role of carvacrol against ESBL E. coli.

Keywords: urinary tract infection, carvacrol, Escherichia coli, extended-spectrum $\beta$-lactamase, reactive oxygen species, europathogen

\section{INTRODUCTION}

Urinary tract infection (UTI), also known as bladder infection, commonly affects women compared to men due to several reasons such as female anatomy, sexual intercourse, family history, etc. Symptoms of UTI include pain in the lower abdomen, fever, fatigue, or bad smelling urine, etc. (Khawcharoenporn et al., 2013; Picozzi et al., 2014). It is important to recognize UTI at an early stage since it creates complications later on for treatment. The most common UTI microorganism is Escherichia coli, although others such as viruses and fungi have been reported (Khawcharoenporn et al., 2013). Multidrug-resistant (MDR) 
bacteria are common in UTI and make this type of infection more difficult to treat with routine antibiotics. In the recent years, extended-spectrum $\beta$-lactamase (ESBL) producing bacteria have become more common in UTI. These bacteria are resistant to the most $\beta$-lactam class of antibiotics due to the production of enzyme $\beta$-lactamase that selectively attacks the $\beta$-lactam ring of antibiotics (Khawcharoenporn et al., 2013; Picozzi et al., 2014). The $\beta$-lactamases are broadly classified into four classes A, B, C, and $\mathrm{D}$ on the basis of their amino acid sequences and named due to mutant forms of ESBL such as SHV, TEM, and CTXMtype $\beta$-lactamases. A variety of mutant lactamases have been discovered which reflect high resistance to $\beta$-lactam antibiotics (Bush and Jacoby, 2010).

The first ESBL microorganism was isolated in 1983 from Germany, after which a slow outbreak was reported worldwide. Many recent articles suggest that ESBL E. coli is one of the main causative agents of UTI (Khawcharoenporn et al., 2013). Ascites is an accumulation of abdominal fluid found in many elderly patients with UTIs and pathogenic bacteria are able to travel through the urine to ascitic fluid, which leads to infection. Therefore, it is important to find potential antimicrobial agents that are effective against ESBL E. coli (Abirami et al., 2012).

In recent years, there have been many reports on the use of essential oil or its components, as potent antimicrobials against a variety of pathogenic bacteria (Di Pasqua et al., 2007; Bajpai et al., 2009). Carvacrol, which is present in essential oils of Origanum vulgare, Thymus vulgaris, Trachyspermum ammi, Lepidium africanum, and Citrus bergamia, has been widely studied as an antimicrobial, antiviral, and anticancer agent (Johny et al., 2010; Dandlen et al., 2011; Nostro and Papalia, 2012; Monte et al., 2014; Honório et al., 2015). Carvacrol is a hydrophobic monoterpene in nature that easily penetrates the cell membranes of bacteria, leading to disruption of cell membrane integrity as well as release of bacterial cell contents (Cristani et al., 2007; Di Pasqua et al., 2007; Magi et al., 2015).

Therefore, the present study was carried out to evaluate the antimicrobial potential of carvacrol along with its role in the motility and invasion behavior of the ESBL E. coli.

\section{MATERIALS AND METHODS}

\section{Bacterial Strain and Chemicals}

In the present study, ESBL-producing E. coli (KBN10P03217) was used which was isolated from the blood sample of the 70-years old male patient and exhibited resistance to several antibiotics, including ceftazidime, amphotericin B, ampicillin, ampicillin/sulbactam, aztreonam, cefazolin, cefepime, cefotaxime, ciprofloxacin, and trimethoprim/sulfamethoxazole. Bacterial sample was received after the ethical clearance from the ethical committee of Kyungpook National University Hospital, Daegu, South Korea. E. coli was grown in Luria-Bertani (LB) medium purchased from Acumedia (Lansing, MI, United States). Carvacrol, with a purity of $\geq 98 \%$, was purchased from SigmaAldrich (St. Louis, MO, United States) and dissolved in
5\% dimethyl sulfoxide (DMSO) (Sigma Aldrich). Phosphatebuffered saline (PBS) with 5\% DMSO was used as a negative control for all experiments.

\section{Antibacterial Assay}

The minimum inhibitory concentration (MIC) of carvacrol was evaluated using the broth micro-dilution technique in LB broth with an initial inoculum of $10^{7}$ cells $/ \mathrm{ml}$ in a nontreated polystyrene microtiter plate CC7672-7596; (CytoOne) in accordance with the Clinical and Laboratory Standards Institute (CLSI). The MIC was interpreted as the lowest concentration of carvacrol that completely inhibited visible growth of the bacteria after $24 \mathrm{~h}$ of incubation at $37^{\circ} \mathrm{C}$. Each concentration was tested in triplicate in at least three independent experiments.

\section{Time Kill Assay}

The viable cell count was evaluated according to the method adopted by Chauhan and Kang (2014). Briefly, mid-log phase E. coli cells $\left(10^{7}\right.$ cells $\left./ \mathrm{ml}\right)$ were inoculated into $\mathrm{LB}$ broth containing carvacrol (MIC) and incubated at $37^{\circ} \mathrm{C}$. At different incubation times such as $0,30,60,90$, and $120 \mathrm{~min}$, the culture was plated onto LB agar medium with appropriate dilutions, followed by incubation at $37^{\circ} \mathrm{C}$ for $24 \mathrm{~h}$. Colonies were counted after the incubation period as indicated above. Simultaneously, the controls without carvacrol were also set up under the same experimental conditions.

\section{Fluorescence Microscopy Staining}

Live and dead cells were evaluated by AO/EB (Acridine orange and ethidium bromide) fluorescent staining (Hameed et al., 2016). Overnight grown E. coli cells $\left(10^{7}\right.$ cells $\left./ \mathrm{ml}\right)$ were treated with or without carvacrol (MIC) for $15 \mathrm{~min}$ at $37^{\circ} \mathrm{C}$. After incubation, cells were harvested by centrifugation, washed with PBS and stained with AO/EB (1:1) $(100 \mu \mathrm{g} / \mathrm{ml})$ for $30 \mathrm{~min}$. After 30 min incubation, cells were washed with PBS and visualized under fluorescent microscope. Similarly, to assess the effect of carvacrol on reactive oxygen species (ROS) and membrane potential, $\mathrm{H}_{2}$ DCFDA [5(6) -Carboxy-2', $7^{\prime}$-dichlorofluorescein diacetate] and rhodamine 123 fluorescent staining was carried out, respectively (Warnes et al., 2012). In brief, E. coli cells $\left(10^{7}\right.$ cells $/ \mathrm{ml}$ ) were treated with or without carvacrol for $15 \mathrm{~min}$ followed by centrifugation to harvest the cells. After washing with PBS, cells were stained in dark for 30 min with $\mathrm{H}_{2}$ DCFDA (10 $\mathrm{mM})$ or rhodamine $123(1 \mu \mathrm{g} / \mathrm{ml})$. Cells were thoroughly washed with PBS and visualized under EPI fluorescent Eclipse TS100 Inverted Routine Microscope with PAXCam software (Nikon TS 100, Japan). All experiments were repeated three times independently and at least three different fields were observed for each culture.

\section{Crystal Violet Uptake Assay}

Alteration of membrane permeability was detected by crystal violet assay (Devi et al., 2010). Suspensions of E. coli $\left(10^{7}\right.$ cells $/ \mathrm{ml}$ ) were prepared in LB broth. Cells were harvested at $10,000 \mathrm{rpm}$ for $5 \mathrm{~min}$. The cells were washed twice and suspended in $50 \mathrm{mM}$ PBS ( $\mathrm{pH} 7.4)$. Carvacrol at MIC was added to the 
cell suspension and incubated at $37^{\circ} \mathrm{C}$ for $30 \mathrm{~min}$. Control samples were prepared similarly without treatment. The cells were harvested at 10,000 rpm for $5 \mathrm{~min}$ and suspended in PBS containing $10 \mu \mathrm{g} / \mathrm{ml}$ of crystal violet. The cell suspension was then incubated for $10 \mathrm{~min}$ at $37^{\circ} \mathrm{C}$ and centrifuged at $10,000 \mathrm{rpm}$ for $5 \mathrm{~min}$, after which the $\mathrm{OD}_{590}$ of the supernatant was measured using a UV-VIS spectrophotometer (UV-2120 Optizen, Mecasys, South Korea). The optical density (OD) value of crystal violet solution, which was originally used in the assay, was considered as $100 \%$ excluded. The percentage of crystal violet uptake for all samples was calculated using the following formula:

$$
\begin{aligned}
\% \text { Dye uptake }= & 100-[(\mathrm{OD} \text { of the sample } / \mathrm{OD} \text { value of crystal } \\
& \text { violet solution }) \times 100]
\end{aligned}
$$

\section{Cellular Material Release}

Measurement of release of cellular materials (DNA) from E. coli cells was carried out by inoculating the mid-log phase culture $\left(10^{7}\right.$ cells $\left./ \mathrm{ml}\right)$ into $\mathrm{NaCl}(0.85 \%)$ in the presence and absence of carvacrol (MIC) and incubated at $37^{\circ} \mathrm{C}$. After incubation for $0,30,60$, and $120 \mathrm{~min}, 1 \mathrm{ml}$ of broth was transferred to an Eppendorf tube, which was centrifuged at 10,000 rpm. The absorbance of the supernatant was then measured at $260 \mathrm{~nm}$ using an UV-VIS spectrophotometer. Results were expressed in the form of OD recorded at each time interval. Simultaneously, the amount of released protein in the presence and absence of carvacrol was determined by using Bradford reagent (Devi et al., 2010). In brief, $5 \mathrm{ml}$ overnight grown cells $\left(10^{7}\right.$ cells $\left./ \mathrm{ml}\right)$ were harvested at $8,000 \mathrm{rpm}$, washed thoroughly three times using normal saline $(0.85 \% \mathrm{NaCl})$ and finally suspended in $1 \mathrm{ml}$ of saline in the presence of carvacrol. A control without carvacrol was also set up under the same experimental conditions. At different time points (60 and $120 \mathrm{~min}$ ), protein release was quantified.

Furthermore, to confirm the damaging effect of carvacrol on E. coli cell membrane, the supernatant of carvacrol-treated bacterial suspensions was subjected to SDS-PAGE (Devi et al., 2010). Initially, bacterial cells were grown to OD 2.0 and then harvested at $10,000 \mathrm{rpm}$ for $5 \mathrm{~min}$ at room temperature; the bacterial pellet was washed twice with $\mathrm{PBS}(\mathrm{pH} 7.4)$ and re-suspended in PBS. Carvacrol at MIC value was added to the cell suspensions, and the samples were incubated at $37^{\circ} \mathrm{C}$ for 60 and $120 \mathrm{~min}$. After treatment, the suspensions were centrifuged at $10,000 \mathrm{rpm}$ for $10 \mathrm{~min}$. Control samples were prepared similarly without carvacrol treatment. The supernatant $(50 \mu \mathrm{l})$ was placed in a centrifuge tube, after which $25 \mu \mathrm{l}$ of sample buffer (1 M Tris$\mathrm{HCl}$ (pH-6.8), 50\% glycerol, 10\% SDS, $10 \% \beta$-mercaptoethanol, $1 \%$ bromophenol blue) was added. The samples were then heated at $100^{\circ} \mathrm{C}$ for $5 \mathrm{~min}$ and loaded onto $12 \%$ SDS-PAGE. Silver staining was performed to analyze the proteins released due to membrane disruption.

\section{Scanning Electron Microscopic Examination}

The potential effect of carvacrol on the cell morphology of E. coli was determined with the help of SEM (Khan and Kang, 2016). In brief, bacterial cells were incubated with or without carvacrol for $1 \mathrm{~h}$, washed three times using PBS ( $\mathrm{pH} 7.4$ ), and then centrifuged at 4,000 rpm. The obtained pellet was suspended in PBS, and a thin smear was prepared on a glass slide, which was further fixed in glutaraldehyde $(2.5 \mathrm{~g} / 100 \mathrm{ml}$; Electron Microscopy Science, United States) for $2 \mathrm{~h}$. After fixation, a dehydration step was performed using an increasing order of ethanol ranging from 50 to $100 \%$, after which the cells were dried with liquid $\mathrm{CO}_{2}$. The dried cells were coated with gold in a sputter coater, and samples were observed under a scanning electron microscope (SEM) (Hitachi-S4300, Japan).

\section{Motility Assay}

To assess the effect of carvacrol on bacterial motility, a colony grown on LB agar was stabbed into semi-solid medium (1\% Bacto tryptone; Difco Laboratories, Detroit, MI, United States), $0.5 \%(\mathrm{w} / \mathrm{v}) \mathrm{NaCl}$, and $0.35 \%$ agar (Difco Laboratories, Detroit, MI, United States) with or without carvacrol at sub-inhibitory concentrations (100 and $150 \mu \mathrm{g} / \mathrm{ml}$ ). Bacterial swarming was assessed after incubating the stabbed E. coli at $37^{\circ} \mathrm{C}$ for $24 \mathrm{~h}$. Motility was further confirmed by the non-quantitative hangingdrop technique (Inamuco et al., 2012). In brief, a droplet of bacterial culture was suspended from a glass coverslip over a microscope slide with a central concavity. The motility of bacterial cells was observed at a magnification of 100x under a light microscope.

\section{Growth Conditions and Cell Lines}

Human colon HCT-116 cell line was purchased from the Korean Cell Line Bank (KCLB) and cultured in RPMI-1640 medium at $37^{\circ} \mathrm{C}$ in $5 \% \mathrm{CO}_{2}$ incubator.

\section{Invasion Protection Assay}

Escherichia coli was grown to mid-log phase in the presence of 100 or $150 \mu \mathrm{g} / \mathrm{ml}$ of carvacrol. Bacterial culture was centrifuged and suspended in RPMI-1640 medium to a density of $1 \times 10^{8}$ cells $/ \mathrm{ml}$. HCT-116 colon cells were grown to confluence in 12-well tissue-culture plates, washed three times with plain medium, and incubated with $1 \mathrm{ml}$ of the bacterial solution for $1 \mathrm{~h}$ at $37^{\circ} \mathrm{C}$. HCT-116 monolayers in wells were washed once with $1 \mathrm{ml}$ of warm plain medium and then incubated for $2 \mathrm{~h}$ with $1 \mathrm{ml}$ of $100 \mathrm{mg} / \mathrm{ml}$ of gentamycin in warm RPMI-1640 medium to kill extracellular bacteria. Cells were washed three times with plain RPMI-1640 medium and finally lysed with 1\% Triton $\mathrm{X}-100$. The number of intracellular bacteria was determined by colony-plating as described above (Khan and Kang, 2016).

\section{MTT Assay}

The cytotoxic effect of carvacrol was first determined by MTT assay (Khan and Kang, 2017) Briefly, $5 \times 10^{4}$ HCT-116 cells/well were incubated in the presence of carvacrol at the concentrations of 50,100 , and $150 \mu \mathrm{g} / \mathrm{ml}$ for $2 \mathrm{~h}$ at $37^{\circ} \mathrm{C}$ in a $\mathrm{CO}_{2}$ incubator. After incubation, cells were treated with MTT solution $(5 \mathrm{mg} / \mathrm{ml})$ to produce dark blue colored formazan crystals, which were further dissolved in $50 \mu \mathrm{l}$ of DMSO. Finally, absorbance was measured at $540 \mathrm{~nm}$ in a microplate reader (Bio-Tek Instrument, Co., Everett, WA, United States). 


\section{Statistical Analysis}

All experiments were carried out in triplicate. The results were expressed as mean \pm standard deviation (SD) of three independent experiments. Statistical significance was calculated using Student's " $t$ " tests. *Represents $P$ values $<0.05$, ${ }^{* *}$ represents $P$ - values $<0.01$, and ${ }^{* * *}$ represents $P$-values $<0.001$.

\section{RESULTS}

\section{Time Killing Assay}

In this assay, carvacrol exhibited a severe detrimental effect on the growth of $E$. coli at MIC $(450 \mu \mathrm{g} / \mathrm{ml})$. Especially, viable cell counts of $E$. coli decreased significantly in the time-dependent manner after exposure of carvacrol. As depicted in Figure 1, log CFU/ml drastically decreased to less than $\log 2 \mathrm{CFU} / \mathrm{ml}$ after $60 \mathrm{~min}$, followed by complete inhibition at $120 \mathrm{~min}$. This proves that carvacrol has a severe toxic effect on the viable count of E. coli, whereas cell number of control sets prepared without carvacrol increased slightly.

\section{Live/Dead Bacterial Cells Evaluation}

Furthermore, live and dead bacterial cells were evaluated by $\mathrm{AO} / \mathrm{EB}$ staining. In AO/EB staining, AO stains live cells, however; EB stains to cells which have lost membrane integrity. AO stained cells give green fluorescence representing live cells while EB gives red fluorescence denoting dead cells. We found a high red color fluorescence in carvacrol treated cells, indicating its toxicity to E. coli (Figure 2).

\section{Reduction of Membrane Potential and ROS Generation in E. coli by Carvacrol}

A crystal violet uptake assay was used to determine the membrane permeability. Uptake of crystal violet by E. coli was $4.8 \%$ in

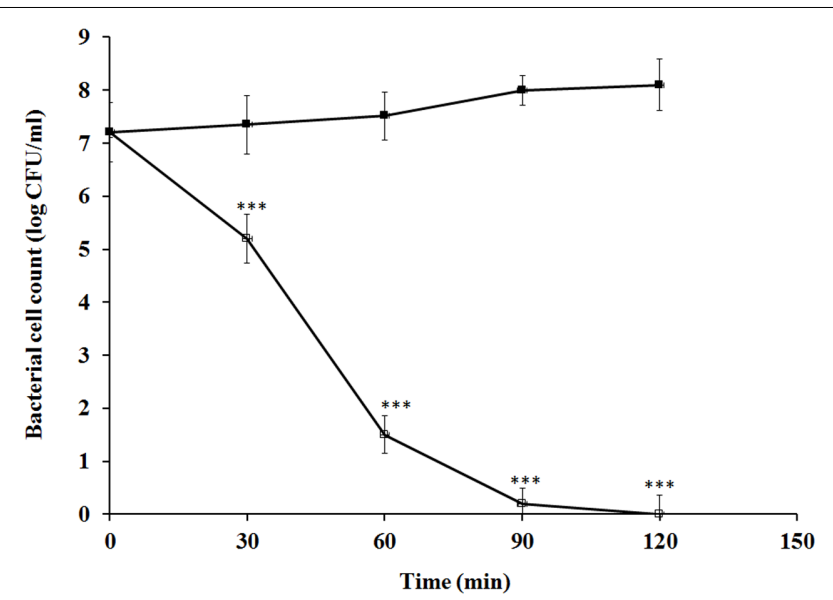

FIGURE 1 | Effects of carvacrol $(450 \mu \mathrm{g} / \mathrm{ml})$ on viable cell counts of Escherichia coli at various time intervals. The data are represented as the means $\pm \mathrm{SD}$ of three independent experiments, ${ }^{* * *} P<0.001 \mathrm{vs}$. control. the absence of carvacrol which increased by 26 and $42 \%$ at 200 and $450 \mu \mathrm{g} / \mathrm{ml}$ (MIC) of carvacrol treatment, respectively (Figure 3A). Furthermore, we investigated the membrane polarization with rhodamine 123. Carvacrol treatment to E. coli for 15 min significantly reduced the fluorescence intensity of rhodamine 123 (Figure 3B) signifying its adverse effect on electrical potential $(\Delta \Psi)$ of bacterial membrane. Moreover, the role of carvacrol on the induction of oxidative stress by the involvement of ROS was observed by $\mathrm{H}_{2}$ DCFDA staining (Figure 3B). The fluorescence dye $\mathrm{H}_{2}$ DCFDA was used to detect the accumulated ROS in the bacterial cell where it is deacetylated by esterase and gives green color that visualized under fluorescence microscope. After treatment with carvacrol for $15 \mathrm{~min}$, ROS level found to be elevated in the $E$. coli representing its impact on the induction of oxidative stress.

\section{Effect of Carvacrol on Cellular Material Release from $E$. coli}

In this assay, carvacrol showed potential to disrupt the cell membrane integrity of $E$. coli, leading to release of cellular materials. As depicted in Figure 4A, carvacrol led to the release of intracellular materials based on absorbance at $260 \mathrm{~nm}$, whereas control experimental sets showed no release of cellular contents. Simultaneously, protein release was detected by using the Bradford method. Protein release serially increased at 60-120 min from 400 to $480 \mu \mathrm{g} / \mathrm{ml}$, in the carvacrol treated cells (Figure 4B). To confirm membrane disintegration of $E$. coli by carvacrol, released membrane proteins were also detected by SDS-PAGE. Intensities of separated bands increased from 60 to $120 \mathrm{~min}$ and showed a distinct banding pattern as compared to control (untreated) (Figure 4C).

\section{Scanning Electron Microscopy}

Scanning electron microscopy was carried out to visualize the effect of carvacrol on cell morphology of E. coli. Carvacrol caused cell membrane lysis, as evident by membrane damage and altered cell morphology unlike to control (untreated) where intact cells were observed (Figure 5).

\section{Reduction of Motility and Colon Cell Protection by Carvacrol}

To determine the suitable concentration of carvacrol for motility and invasion experiments, we plotted a growth curve with different concentrations of carvacrol $(0-250 \mu \mathrm{g} / \mathrm{ml})$. As a results, no significant growth inhibition of $E$. coli was observed at 100 and $150 \mu \mathrm{g} / \mathrm{ml}$ (Figure 6A). Moreover, carvacrol did not exert the cytotoxic effect on HCT-116 colon cells as determined by MTT assay (Figure 6B). Furthermore, carvacrol showed a significant effect on the bacterial motility at the sublethal concentrations of 100 and $150 \mu \mathrm{g} / \mathrm{ml}$. At $150 \mu \mathrm{g} / \mathrm{ml}$ concentration of carvacrol, E. coli showed minimum motility with $39 \%$ relative zone diameter as compared to $100 \%$ in the control (untreated) (Figure 6C). Light microscopy results of the hanging drop assay revealed complete loss of motility at concentration $150 \mu \mathrm{g} / \mathrm{ml}$ of carvacrol (data not shown). 


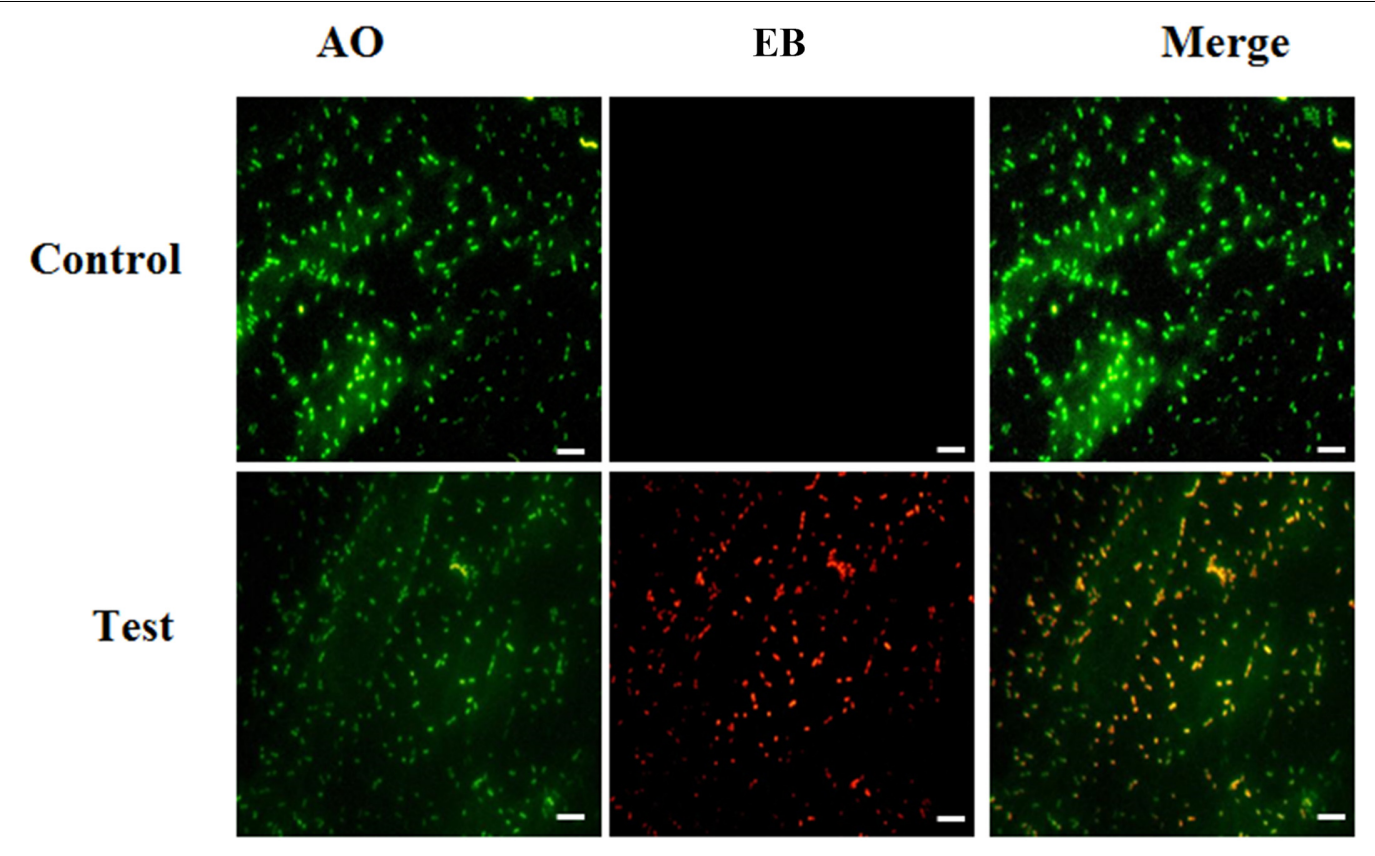

FIGURE 2 | Microscopic assessment of E. coli after treatment with carvacrol. The bacterial cell death was examined via AO/EB staining and fluorescent microscopy. Live bacteria emit green fluorescence, and dead bacteria as red fluorescence [Scale bar $=10 \mu \mathrm{m}$ ].
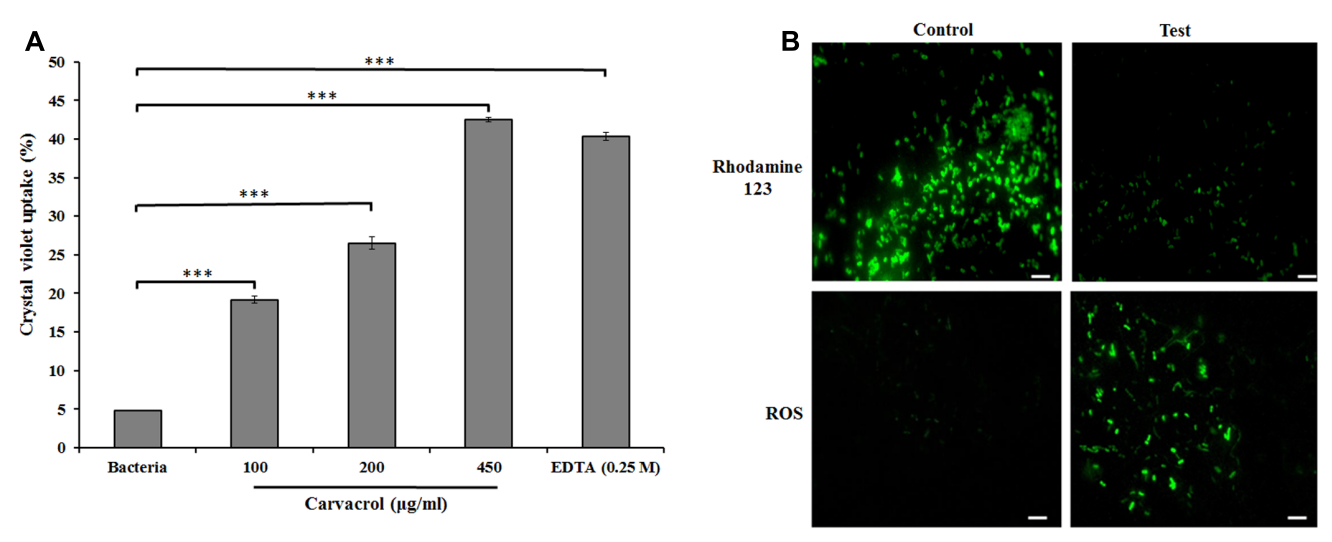

FIGURE 3 | (A) Crystal violet uptake of carvacrol (100-450 $\mu \mathrm{g} / \mathrm{ml})$-treated E. coli. EDTA (0.25 M), was used as a positive control. The data are represented as the means $\pm \mathrm{SD}$ of three independent experiments, ${ }^{* * *} P<0.001 \mathrm{vs}$. control. (B) Effect of carvacrol on E. coli membrane potential, using lipidophilic stain rhodamine 123 (Rh123). Bacterial cells were incubated with or without carvacrol (450 $\mu \mathrm{g} / \mathrm{ml})$ for 15 min and then stained with Rh123. Cells with intact membranes stain brightly due to accumulation of Rh123, however if the membrane is compromised the potential is lost and staining dissipates. Generation of reactive oxygen species (ROS) in $E$. coli by $\mathrm{H}_{2}$ DCFDA staining. Bacterial cells were incubated with or without carvacrol $(450 \mu \mathrm{g} / \mathrm{ml})$ for $15 \mathrm{~min}$ then stained with $\mathrm{H}_{2} \mathrm{DFFDA}$ [Scale bar = $10 \mu \mathrm{m}$ ]. All the fluorescent images visualized under EPI fluorescent Eclipse TS100 Inverted Routine Microscope with a PAXCam software (Nikon TS 100, Japan).

Furthermore, E. coli cells pretreated with carvacrol showed decreased invasion to HCT-116 colon cells as compared to control (untreated) (Figure 6D). E. coli cells pretreated with $150 \mu \mathrm{g} / \mathrm{ml}$ carvacrol represent $31 \pm 3.2 \%$ invasions as compared to the $100 \%$ invasion of the control.

Two concentrations of carvacrol 100 and $150 \mu \mathrm{g} / \mathrm{ml}$ were considered as sub-lethal as bacterial cells were found to grow freely in these concentrations. The finding suggests that carvacrol has strong inhibitory effects against bacterial invasion and motility.

\section{DISCUSSION}

Urinary tract infection is one of the most common diseases worldwide and occurs mainly in women. In UTIs, the microflora is mainly composed of E. coli, Klebsiella pneumoniae, and Pseudomonas aeruginosa and is predominated by E. coli (Khawcharoenporn et al., 2013; Picozzi et al., 2014). These bacteria are able to cause issues due to anatomical changes and poor maintenance of personal hygiene during pregnancy. Moreover, E. coli has a unique structure that allows it to 

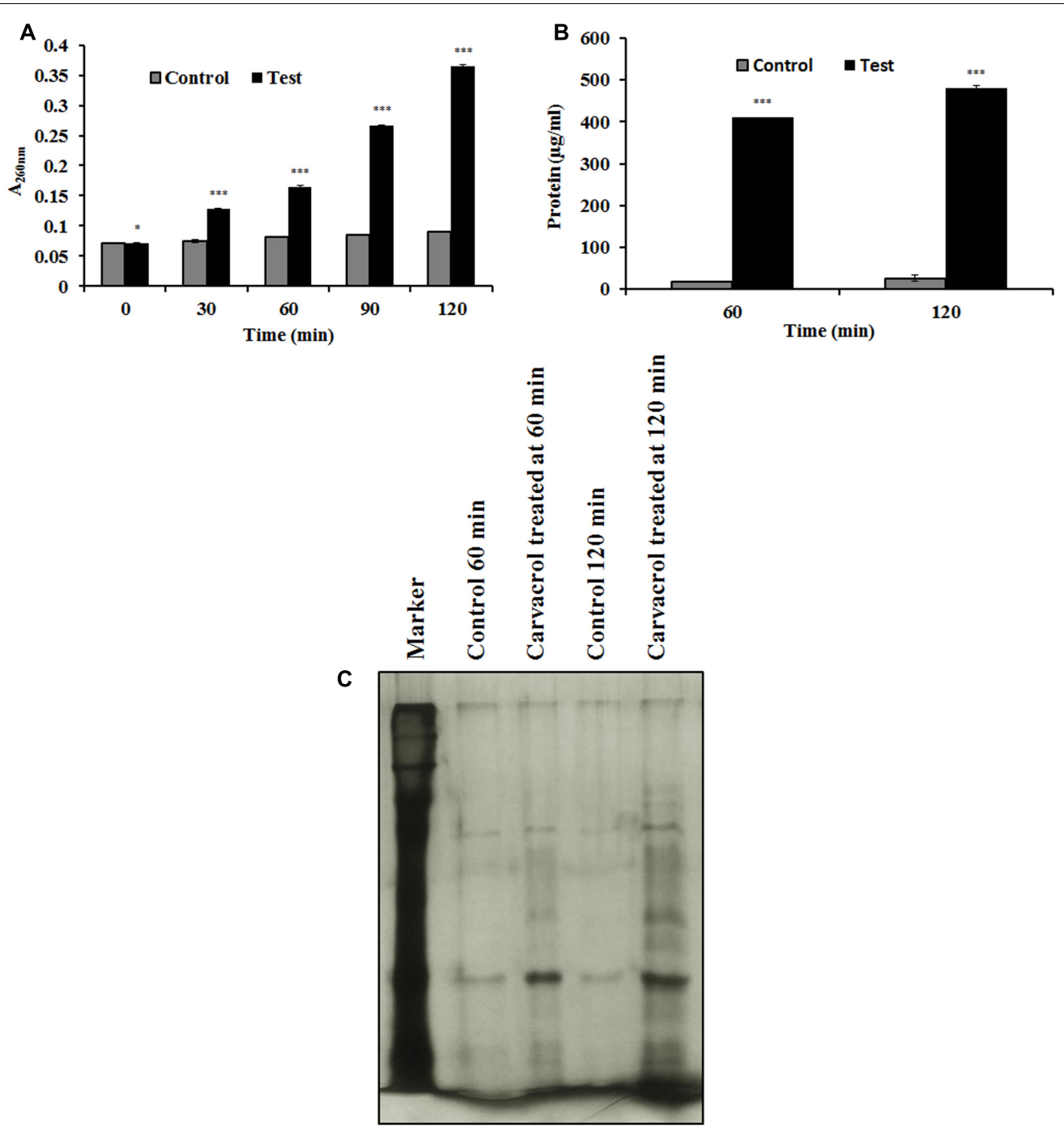

FIGURE 4 | (A) Effects of carvacrol on release of cellular materials from E. coli based on absorbance value recorded at $260 \mathrm{~nm}$. (B) Protein release due to carvacrol treatment. (C) Time-dependent proteins released into supernatant by carvacrol treatment (MIC), detected by using SDS-PAGE. Lane-2 and lane-3 represent control and carvacrol treatment at $60 \mathrm{~min}$; lane- 4 and lane- 5 represent control and carvacrol treatment at 120 min, respectively. Bar diagrams are depicted as the means $\pm \mathrm{SD}$ of three independent experiments, ${ }^{*} P<0.05,{ }^{* * *} P<0.001$ vs. control.

attach to uroepithelial cells, invade, and spread intracellularly, ultimately leading to pyelonephritis (Khawcharoenporn et al., 2013). Furthermore, E. coli has the ability to travel way through the urinary tract to ascites, resulting in ascitic fluid infection (Abirami et al., 2012). Due to the severity of E. coli infection and its resistance toward $\beta$-lactam antibiotics, a potent agent with the ability to kill this uropathogen and simultaneously protect mammalian cells from infection is needed.

Natural compounds are used to treat infectious diseases worldwide (Ndjonka et al., 2013). Most of these compounds are hydrophobic, which grants strong antimicrobial properties against Gram-negative bacteria. Many essential oils and their components have antimicrobial activities against foodborne pathogens, with carvacrol used in the food industry as a food additive (Cristani et al., 2007; Yu et al., 2012; Yang et al., 2015).
In our study, we used carvacrol due to its hydrophobic nature and its potential as an antimicrobial agent (Nostro and Papalia, 2012). Our results suggest that carvacrol has potent antimicrobial activity against ESBL E. coli isolated from ascetic fluid of UTI patients, as it reduced the viable bacterial count at MIC. Previously, similar kinds of inhibitory effects of carvacrol have been reported against Salmonella enteritidis and Campylobacter jejuni (Johny et al., 2010).

Any effective antimicrobial compound must either penetrate or disrupt the bacterial plasma membrane. In the present study, carvacrol disrupted the E. coli membrane, leading to release of cellular contents as confirmed based on the absorbance values measured at $260 \mathrm{~nm}$. Most of antimicrobial agents rupture bacterial membrane via membrane disintegration and generation of ROS. Here, we observed that carvacrol induces enhanced 


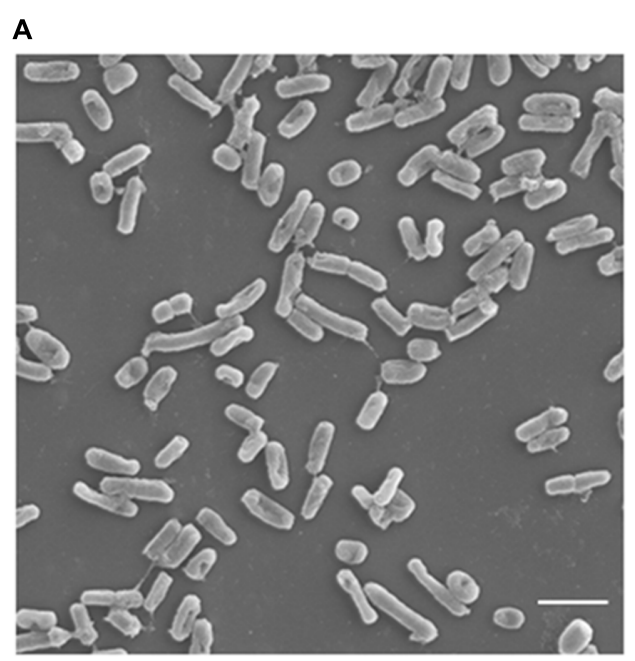

B

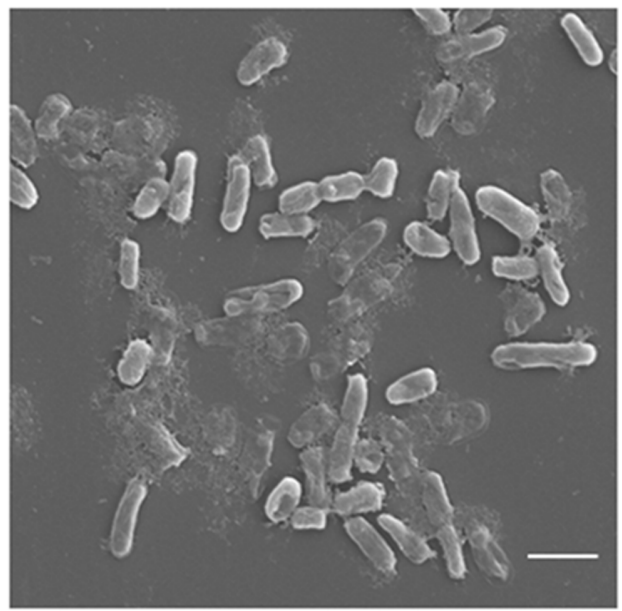

FIGURE 5 | Scanning electron microscopic analysis of $E$. coli. (A) Represents cells without any treatment showing regular and intact cell morphologies. (B) Cells treated with carvacrol at MIC $(450 \mu \mathrm{g} / \mathrm{ml})$ showing distorted bacterial cell wall morphology (Scale bar $=2.5 \mu \mathrm{m})$.
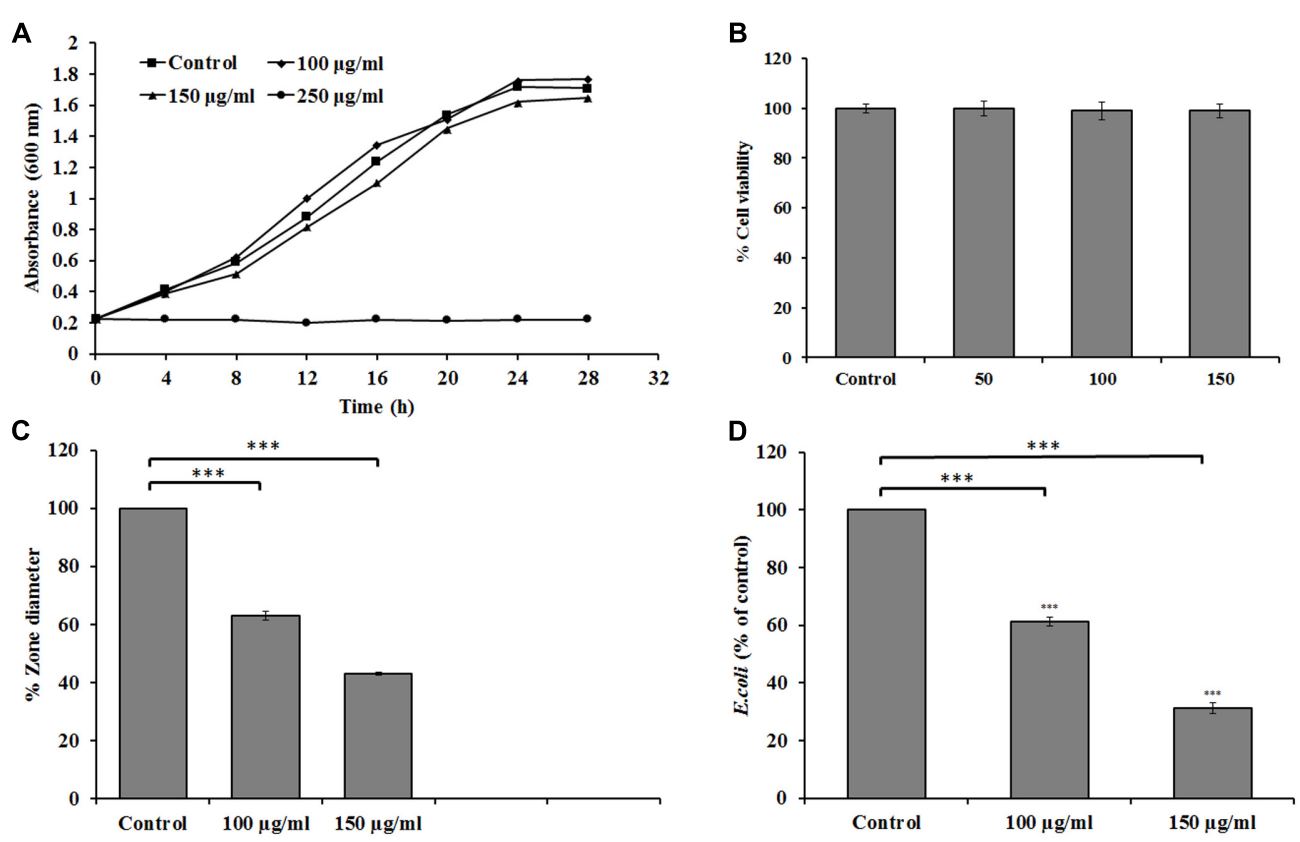

FIGURE 6 | (A) Swarming of E. coli in soft agar plates. (A) Representative growth curve of $E$. coli in the presence of different concentrations of carvacrol [0 (control), 100, 150, and $250 \mu \mathrm{g} / \mathrm{mll}$. Each reading measured in triplicates and in three independent experiments. (B) MTT assay evaluation of carvacrol on HCT-116 colon cells after $2 \mathrm{~h}$. (C) Relative zone diameter compared to the control without carvacrol. (D) Invasion of colon cells by E. coli, presented as \% relative to control without carvacrol (100 and $150 \mu \mathrm{g} / \mathrm{ml})$. The data are represented as the means \pm SD of three independent experiments, ${ }^{* * *} P<0.001$ vs. control.

crystal violet uptake which denotes that there was an increasing level of membrane leakage, thus changed the membrane permeability. Moreover, the membrane depolarization was also validated using rhodamine 123 fluorescence dye. During the initiation of cell death mechanism, ROS generation found to play a crucial role to initiate cessation of cell. In this study, we confirmed the enhanced level of ROS in E. coli cells after treatment with carvacrol using $\mathrm{H}_{2}$ DCFDA dye. The finding suggests a highly oxidative stress environment inside the $E$. coli in response to carvacrol. A high oxidative stress is well-associated with adverse effect on cell components such as DNA and protein (Warnes et al., 2012).

Furthermore, SEM analysis revealed that carvacrol interacted with the lipid bilayer of bacterial cells and induced structural disruption. These results are similar to the previous findings where thymol as an isomer of carvacrol was able to disrupt the 
bacterial plasma membrane and caused the release of cellular contents (Chauhan and Kang, 2014).

Although some antibiotics are effective in treating UTIcausing pathogens, but fail to provide protection against bacterial virulence such as invasion or intracellular killing. Therefore, an antimicrobial should be able to inhibit the motility of bacteria in order to protect mammalian cells from invasion. Hence, we evaluated the role of carvacrol to protect colon cells from E. coli invasion. To achieve this, we treated $E$. coli cells with a sub-lethal concentration of carvacrol and carried out infection of colon cells. Carvacrol effectively reduced motility and invasion, which showed a positive correlation. The data obtained from this study indicate that carvacrol has the ability to protect colon cells from E. coli invasion and could affect the functionality of the bacterial flagellum, which is in accordance with a study done by Inamuco et al. (2012).

\section{CONCLUSION}

Carvacrol has the ability to disrupt the membrane integrity of $E$. coli, resulting in the release of cellular contents (DNA

\section{REFERENCES}

Abirami, K., Sivaramakrishna, G., Lakshmi, A. Y., and Sivakumar, V. (2012). Urinary ascites. Indian J. Nephrol. 22, 143-144. doi: 10.4103/0971-4065.97140

Bajpai, V. K., Al-Reza, S. M., Choi, U. K., Lee, J. H., and Kang, S. C. (2009). Chemical composition, antibacterial and antioxidant activities of leaf essential oil and extracts of Metasequioa glyptostroboides miki ex hu. Food Chem. Toxicol. 47, 1876-1883. doi: 10.1016/j.fct.2009.04.043

Bush, K., and Jacoby, G. A. (2010). Updated functional classification of $\beta$-lactamases. Antimicrob. Agents Chemother. 54, 969-976. doi: 10.1128/AAC. 01009-910.1128/AAC.01009-09

Chauhan, A. K., and Kang, S. C. (2014). Thymol disrupts the membrane integrity of Salmonella ser. typhimurium in vitro and recovers infected macrophages from oxidative stress in an ex vivo model. Res. Microbiol. 165, 559-565. doi: 10.1016/j.resmic.2014.07.001

Cristani, M., D’Arrigo, M., Mandalari, G., Castelli, F., Sarpietro, M. G., Micieli, D., et al. (2007). Interaction of four monoterpenes contained in essential oils with model membranes: implications for their antibacterial activity. J. Agric. Food Chem. 55, 6300-6308. doi: 10.1021/jf070094x

Dandlen, S. A., Lima, A. S., Mendes, M. D., Miguel, M. G, Faleiro, M. L., Sousa, M. J., et al. (2011). Antimicrobial activity, cytotoxicity and intracellular growth inhibition of Portuguese Thymus essential oils. Braz. J. Pharm. 21, 1012-1024. doi: 10.1590/S0102-695X2011005000155

Devi, K. P., Nisha, S. A., Sakthivel, R., and Pandian, S. K. (2010). Eugenol (an essential oil of clove) acts as an antibacterial agent against Salmonella typhi by disrupting the cellular membrane. J. Ethnopharmacol. 130, 107-115. doi: 10.1016/j.jep.2010.04.025

Di Pasqua, R., Betts, G., Hoskins, N., Edwards, M., Ercolini, D., and Mauriello, G. (2007). Membrane toxicity of antimicrobial compounds from essential oils. J. Agric. Food Chem. 55, 4863-4870. doi: 10.1021/jf0636465

Hameed, A. S. H., Karthikeyan, C., Ahamed, A. P., Thajuddin, N., Alharbi, N. S., Alharbi, S. A., et al. (2016). In vitro antibacterial activity of $\mathrm{ZnO}$ and $\mathrm{Nd}$ doped $\mathrm{ZnO}$ nanoparticles against ESBL producing Escherichia coli and Klebsiella pneumoniae. Sci. Rep. 6:24312. doi: 10.1038/srep24312

Honório, V. G., Bezerra, J., Souza, G. T., Carvalho, R. J., Gomes-Neto, N. J., Figueiredo, R. C., et al. (2015). Inhibition of Staphylococcus aureus cocktail using the synergies of oregano and rosemary essential oils or carvacrol and 1,8-cineole. Front. Microbiol. 6:1223. doi: 10.3389/fmicb.2015.01223

Inamuco, J., Veenendaal, A. K., Burt, S. A., Post, J. A., Tjeerdsma-van Bokhoven, J. L., Haagsman, H. P., et al. (2012). Sub-lethal levels of carvacrol reduce and proteins), and protect colon cells from bacterial invasion. Based on findings, it can be concluded that carvacrol could be a potent antimicrobial candidate against ESBL E. coli causing UTIs in women population. Though there have been many previous reports on the antimicrobial action of various agents against $E$. coli, this is the first report on the action of carvacrol against UTI-causing ESBL E. coli, and its effects on motility and invasion.

\section{AUTHOR CONTRIBUTIONS}

IK and $A B$ : Designed and performed the experiments and initially wrote the manuscript. PK, VB, and SK: Critically edited and finalized the manuscript.

\section{ACKNOWLEDGMENT}

We thank to Prof. Jung Won Yoon, Daegu University, South Korea, for his technical support on our manuscript.

Salmonella Typhimurium motility and invasion of porcine epithelial cells. Vet. Microbiol. 157, 200-207. doi: 10.1016/j.vetmic.2011.12.021

Johny, A. K., Darre, M. J., Donoghue, A. M., Donoghue, D. J., and Venkitanarayanan, K. (2010). Antibacterial effect of trans-cinnamaldehyde, eugenol, carvacrol, and thymol on Salmonella enteritidis and Campylobacter jejuni in chicken cecal contents in vitro. J. Appl. Poult. Res. 19, 237-244. doi: 10.3382/japr.2010-00181

Khan, I., and Kang, S. C. (2016). Probiotic potential of nutritionally improved Lactobacillus plantarum DGK-17 isolated from Kimchi-a traditional Korean fermented food. Food Control 60, 88-94. doi: 10.1007/s12602-014-9158-2

Khan, I., and Kang, S. C. (2017). Apoptotic activity of Lactobacillus plantarum DGK-17-fermented soybean seed extract in human colon cancer cells via ROSJNK signaling pathway. J. Food Sci. 82, 1475-1483. doi: 10.1111/1750-3841. 13732

Khawcharoenporn, T., Vasoo, S., and Singh, K. (2013). Urinary tract infections due to multidrug-resistant enterobacteriaceae: prevalence and risk factors in a Chicago emergency department. Emerg. Med. Int. 2013:258517. doi: 10.1155/ 2013/258517

Magi, G., Marini, E., and Facinelli, B. (2015). Antimicrobial activity of essential oils and carvacrol, and synergy of carvacrol and erythromycin, against clinical, erythromycin-resistant group a streptococci. Front. Microbiol. 3:165. doi: $10.3389 /$ fmicb.2015.00165

Monte, D. F. M., Tavares, A. G., Albuquerque, A. R., Sampaio, F. C., Oliveira, T. C. R. M., Franco, O. L., et al. (2014). Tolerance response ofmultidrug-resistant Salmonella enterica strains to habituation to Origanum vulgare L essential oil. Front. Microbiol. 5:721. doi: 10.3389/fmicb.2014. 00721

Ndjonka, D., Rapado, L. N., Silber, A. M., Liebau, E., and Wrenger, C. (2013). Natural products as a source for treating neglected parasitic diseases. Int. J. Mol. Sci. 14, 3395-3439. doi: 10.3390/ijms14023395

Nostro, A., and Papalia, T. (2012). Antimicrobial activity of carvacrol: current progress and future prospectives. Recent Pat. Antiinfect. Drug Discov. 7, 28-35. doi: 10.2174/157489112799829684

Picozzi, S. C., Casellato, S., Rossini, M., Paola, G., Tejada, M., Costa, E., et al. (2014). Extended-spectrum beta-lactamase-positive Escherichia coli causing complicated upper urinary tract infection: urologist should act in time. Urol. Ann. 6, 107-112. doi: 10.4103/0974-7796.130536

Warnes, S. L., Caves, V., and Keevil, C. W. (2012). Mechanism of copper surface toxicity in Escherichia coli O157:H7 and Salmonella involves immediate membrane depolarization followed by slower rate of DNA destruction which 
differs from that observed for gram-positive bacteria. Environ. Microbiol. 14, 1730-1743 doi: 10.1111/j.1462-2920.2011.02677.x

Yang, X. N., Khan, I., and Kang, S. C. (2015). Chemical composition, mechanism of antibacterial action and antioxidant activity of leaf essential oil of Forsythia koreana deciduous shrub. Asian Pac. J. Trop. Med. 8, 694-700. doi: 10.1016/j. apjtm.2015.07.031

Yu, H., Zhang, Z. L., Chen, J., Pei, A., Hua, F., Qian, X., et al. (2012). Carvacrol, a food-additive, provides neuroprotection on focal cerebral ischemia/reperfusion injury in mice. PLOS ONE 7:33584. doi: 10.1371/journal. pone. 0033584
Conflict of Interest Statement: The authors declare that the research was conducted in the absence of any commercial or financial relationships that could be construed as a potential conflict of interest.

Copyright $\odot 2017$ Khan, Bahuguna, Kumar, Bajpai and Kang. This is an open-access article distributed under the terms of the Creative Commons Attribution License (CC BY). The use, distribution or reproduction in other forums is permitted, provided the original author(s) or licensor are credited and that the original publication in this journal is cited, in accordance with accepted academic practice. No use, distribution or reproduction is permitted which does not comply with these terms. 